\title{
The Relationship between Teaching Transactional Analysis Theory and College Students' Locus of Control: an Empirical Research
}

\author{
(C) 2010 Yang Mei
}

\begin{abstract}
An investigation, through empirical research, of the relationship between education in Transactional Analysis theory and the Locus of Control of college students. Two questionnaire surveys were conducted before and after the Transactional Analysis classes, and personal narrative reports by the students were collected. It was found that psychology education in Transactional Analysis correlated with a reduction in scores for the External Control proclivity of the 81 students, and their assignments displayed similar proclivity. Transactional Analysis knowledge was shown to help students discover and explore their own potentials and liberate their creativity. It is proposed that an increase of transactional analysis theory in the education of college students should be considered.
\end{abstract}

\section{Keywords:}

Locus of control, college students, Transactional Analysis, psychology education, empirical research, ANSIE.

\section{The problem}

The term "locus of control" was first proposed by J. B. Rotter in 1966 to express the generalized expectancy or belief of the relationship between one's personality and behaviour and event results. It includes internal control and external control (Wang 1993a).

Those with a high internal control believe that the outcome is closely related to their actions, and they tend to attribute the results to individual control. Hence, they are responsible for their behaviour, they work hard, devote themselves to social activities and influence others, and usually feel more happiness. On the other hand, those who have a high external control, due to their belief that "the result is regardless of one's efforts", tend to attribute results to the outside environment, such as powerful others, fate or chance. Thus they are more negative in dealing with matters and more liable to feel anxious or depressed, and have difficulty tackling intense living environments (Hunt 1999).

As an important variable that influences a person's psychology and behaviour the locus of control is significant in its predictive functions of a person's psychology and behaviour. It has attracted attentions of foreign researchers since it was first proposed. Researchers in China began to focus on it in the 1990s.

The author searched the China Academic Journals Fulltext Database, from 1981 to 2009, with the descriptors "locus of control" and "college student", and got 20 results of publications. Most of the articles researched the locus of control from a perspective of its relationships with psychological health, sense of happiness, altruism, time management, social expectations, etc.

The sense of control has a significant influence on the mental health of the normal population. "Plenty of research has confirmed that the external control is related with anxiety, depression and other emotions. Those with a strong external control have more difficulty dealing with intense living environments. However, a person with a strong internal control will be more positive in seeking valuable goals, participate in more social activities, and has more flexibility, self-assertiveness and sense of happiness" (Zhao et al 2007).

Among the normal population, college students are also under significant influence of locus of control. In order to consolidate their mental health, their internal control may be strengthened by means of counselling or psychology education. 
So far, there are very few reports of empirical research on counselling or educational prevention concerning locus of control in China. One article mentioned that mental health education in one particular university effectively increased the internal control points of 78 students, but did not specify the content and time of such psychology education (Zhu 2008).

In previous research on a cognitive-behaviouralemotional management training group concerning college students' anxiety of tests, the author utilized the Adult Nowicki-Strickland Internal-External Control Scale as research instrument. Results of the pre-test and posttest showed that the 7 students that participated in the group had significantly lower scores in external control. Because the Adult Nowicki-Strickland Internal-External Control Scale is calculated in terms of the score in the external control, the decrease of the external control means the increase of the internal control (Yang 2002).

In 1999, the author taught a Personality Psychology course to 99 sophomore students every week; each class session lasted two hours, for 17 weeks and amounting to 34 hours in total. One of the research instruments that the author employed in the class was the Adult Nowicki-Strickland Internal-External Control Scale, and the results showed that the students had significant decrease $(P<0.001)$ of their external control after the Personality Psychology course (Yang 1999).

Over recent years, the author has become increasingly aware of the exceptional potential that Transactional Analysis has to enhance people's mental health, and thus decided to conduct empirical research in her own classes of the effect of TA training on college students' locus of control.

Transactional Analysis (TA) is a personality theory as well as a systematic method of interpersonal communication. In terms of personality theory, TA has a set of specific and easy-to-understand means of expression, which is suitable for people's self-awareness and growth. On the other hand, TA also contains a set of highly operable analytic approaches to communication, and can thus help people communicate in a more effective way.

\section{Hypothesis:}

Education in transactional analysis psychology will correlate with an increase in internal locus of control in college students.

\section{Ethics}

All students were invited to opt in to the research and were advised that failure to do so would not have any impact on their status in the class, the marking of their assignments or their course results. The four who were not included did not complete the pre-post tests.
The participants were assured that all information collected, through the tests and also from their assignments, would be treated as confidential and their identities would not be revealed.

\section{Subjects and Methods}

\section{Subjects}

85 full-time students from the Capital University of Economics and Business in Beijing, who voluntarily selected the course of Transactional Analysis.

Data was collected for 81 students, 17 male and 64 female.

\section{Methods}

Psychological Education

Introduction of Transactional Analysis by means of psychology classes covering seven areas of TA: the three ego states of personality, contamination and decontamination, the four life positions, strokes and discounts, means of interpersonal communication and analysis, psychological games, life scripts, early decisions, and redecisions.

\section{Measurements}

The Adult Nowicki-Strickland Internal-External Control Scale (ANSIE) designed by Nowicki and Duke in 1974 was adopted in the research (Wang 1993b).

The ANSIE Control Scale assesses the generalized expectancy of locus of control with internal control and external control as two ends of the continuum. It comprises 40 self-rated items, and the score ranges from 0 (internal control) to 40 (external control).

\section{Narrations}

Parts of the students' home work assignments were selected and excerpted. The students' writings speak for themselves, and allow concrete glimpses of the students' changes and growth.

\section{Time}

From February to June 2009, the time amounted to 17 weeks, among which two weeks were holidays and one was examination. There was thus 14 weeks' time of class sessions, or 28 hours. Classes were given once a week for two hours per week.

\section{Analysis}

Two surveys were conducted using the ANSIE Scale in the first and last class. Results of the two surveys were processed and analyzed with SPSS statistics software and corresponding significance tests were made. 


\section{Results}

Note: Because the questionnaire was calculated in terms of the scores of external control, the higher the scores, the higher the external control.

Comparison of differences of external control between the pre- and post-test by all the students that attended the class.

Table 1 Means and SDs of the Pre- and Post-test

\begin{tabular}{lcc}
\hline $\mathbf{n}=\mathbf{8 1}$ & Mean & SD \\
\hline Pre-test & 12.16 & 4.16 \\
Post-test & 11.02 & 4.14 \\
\hline
\end{tabular}

Table 2 Comparison of differences of external control between the Pre- and Post-test

\begin{tabular}{|c|c|c|c|c|}
\hline$n=81$ & Mean & SD & $t$ & $\mathbf{p}$ \\
\hline $\begin{array}{l}\text { Pre-test - Post- } \\
\text { test }\end{array}$ & 1.14 & 3.64 & 2.8 & $0.01^{* \star}$ \\
\hline
\end{tabular}

It is shown in Table 1 and 2 that the mean score of the Post-test is significantly lower than that of the Pre-test, so students' external control has significantly decreased $(\mathrm{P}<0.01)$.

Comparison of differences of external control between the pre- and post-test by students of different genders

Table 3 Comparison of differences of students of different genders between the pre- and post-test

\begin{tabular}{|c|c|c|c|c|c|c|}
\hline & \multicolumn{2}{|c|}{ Male $(n=17)$} & \multicolumn{2}{|c|}{ Female $(n=64)$} & \multirow[b]{2}{*}{$t$} & \multirow[b]{2}{*}{$\mathbf{p}$} \\
\hline & Mean & SD & Mean & SD & & \\
\hline $\begin{array}{l}\text { Pre- } \\
\text { test }\end{array}$ & 9.76 & 3.29 & 12.80 & 4.16 & -2.78 & $0.01^{* *}$ \\
\hline $\begin{array}{l}\text { Post- } \\
\text { test }\end{array}$ & 9.59 & 4.06 & 11.40 & 4.11 & -1.63 & 0.11 \\
\hline $\begin{array}{l}\text { Pre- } \\
\text { test - } \\
\text { Post- } \\
\text { test }\end{array}$ & -0.177 & 3.89 & -1.39 & 3.56 & -1.62 & 0.11 \\
\hline
\end{tabular}

It is shown in Table 3 that the female students' external control in the pre-test is significantly higher than the male students', but in the post-test and in the difference between the two tests, no such significant difference exists. This illustrates how the participating female students originally were more dependent, but after studying transactional analysis their outside dependency decreased to levels not significantly different from those of the male students.

Narration: Changes shown in the students' assignments

During the classes, students had two assignments and one examination. Below follow some illustrative excerpts from the students' written assignments. A fuller account of the students' reports appears in Yang (2009).

\section{Assignment 1}

"I want to be a free child within boundaries, bring out my strong qualities and have control of my behaviour. I'll do my best to refrain from impulsive behaviours that may embarrass others, and improve my mind in this way." (Class of 2008, Humanities College, Guo Hao)

"After learning Transactional Analysis, I often reflect on myself, about how different ego-states change in me, and I ask questions like why haven't I found a combination of them most suited to myself. I think, the most important ego-state that is lacking in me is an adult ego-state. I used to be quite emotional and impulsive in dealing with matters, and lacked rational understanding and judgment, thus couldn't analyze things objectively. And all those are my drawbacks. From now on, I'll try to treat others with the nurturing parent ego-state, caring and giving away warmth to others. As for myself, I'll switch to the child egostate sometimes, so as to release my mind. In a word, I need to adopt an appropriate ego-state at the right time and place. Since these ideas dawned on me, I have felt quite relieved and less harsh in doing things. Although I cannot live up to this objective at the present moment, I will try my best. And this totally lightens my life up, just like opening a window in a dark room." (Class of 2008, Electronic Business, Business Administration College, Lu Sisi)

\section{Assignment 2}

"I have never been so concerned as now about the things that happen, about the people around me, and, of course, about myself. Paying attention to the strokes others give to me, to the communication between us, and to the games we play, seems to have coloured up my life in one blow, and there's always a reason for everything... There was the moment when I saw myself change. And that moment was beyond happiness." (Class of 2008, Humanities College, Li Yan)

"There has always been self-denial in my heart, and most of my orientations of life are 'I am not OK, you are OK' or 'I am not OK, and you are not OK either'. This is inferiority, dependence, powerlessness, selfabandonment, and diffidence, and this way of life is a retiring one and always begging for others' compliments. 
Thinking of TA theory, I think my present situation is closely related with the living environment of my childhood. When I was a kid, my parents liked to compare me with other kids, which might have a positive side of prodding me to pursue a certain goal. However, it also had negative influences, in that it made me feel that there are always people doing better than I. As soon as I have made some achievement out of painstaking efforts, there would always be someone that did better than me. Such endless comparisons have worn out my confidence, and I have gradually retired into a state of self-denial. I dare not keep a high profile. Even if I really excel at what I do, I always fear that there's someone better, and I have just gradually developed this inferior attitude.

After learning this theory, I try to change my way of thinking and alter my conception that others are superior to me... Although everyone's script is determined by their own experience with their own hands, they can still rewrite the script if they want to, or they can rewrite their roles in the script, changing the victim $(\mathrm{V})$, the rescuer $(R)$, or the persecutor $(P)$ to the role of constructor." (Class of 2008, Urban College, Yang Zhe)

\section{Discussion}

The present study needs, of course, further improvement. For instance, the study didn't have a comparative group, and participant subjects were those who voluntarily attended the TA course. If the entire class is selected as subjects, future research is desired on whether the new sampling scheme will have the same positive effect. Lack of comparison group limits results to establishment of correlation rather than causality.

It is also possible that factors other than TA influence the results, like personality and skills of the teacher, the relationship between the teacher and the students, and the teacher's wish to help the students increase their locus of control. Factors like these could be better controlled by studying several groups taught by different teachers.

The distinction between transactional analysis and other forms of psychological knowledge also needs to be further studied. In Yang (1999) positive correlations were also found, even though the content at that time was not TA, so research comparing TA with other psychological courses is also called for.

\section{Conclusion}

The application of Transactional Analysis in systematic psychology education for the students correlated with an increase in their internal control. Previous studies have confirmed that the increase of the internal control has positive influence on the students' mental health, sense of happiness, the concept and ability of time management, sense of self-value, altruism, and others (Zhao et al 2007, Zhang 2009, Ding \& Zhang 2008, Zhang 2003, Yao 2009).
At present, the psychology education for college students in China usually consists of different topics of education, such as motivation, emotion, learning methods, interpersonal relationship, psychology of love, life planning, etc. This knowledge and associated methods play an important role in the strengthening of college students' psychological health and their sense of happiness. At the same time, college students' characteristics should be considered, and specifically their strong curiosity for knowledge, and their strong understanding and analytic capability. Hence, the abovementioned patchwork of different topics for the education can hardly answer to the needs of college students, and may fail to have enduring effects on them. Theories characteristically may have enduring bearings, so an increase of systematic psychological theories should be considered in the psychology education for college students.

Although causality has not been proved, it seems highly likely that the inclusion of TA theory within such teaching can significantly help college students discover and explore their own potentials and liberate their creativity.

The author is Professor of Psychology at Psychology Counseling Center, Capital University of Economics and Business, Beijing China and can be contacted at mayoung@263.net

The author expresses her special appreciation for Dr. Thomas Ohlsson!

\section{References}

Ding, Y. Y. \& Zhang L. N. (2008). The relationship of college students' subjective happiness and their locus of control. China Electric Power Education. 121, 194.

Hunt, M. (1999). The story of psychology. Trans. by Li Si. Haikou: Hainan Press, 433-435.

Wang, X. D. (1993a). Mental Health Assessment Scale Handbook. Chinese Mental Health Journal. Additional Issue, 264-266.

Wang, X. D. (1993b). Mental Health Assessment Scale Handbook. Chinese Mental Health Journal. Additional Issue, 273.

Yang, M. (1999). College students' locus of control and its influence: an experimental research. China Adult Education 12, 106-107.

Yang, M. (2002). A Study on CBEMGT for reducing students Test Anxiety. Health Psychology Journal. 10 (3), 192.

Yang, M. (2009). Transactional Analysis Helps Chinese Undergraduates Live Well. The Script, 39(5)

Yao, J. J. (2009). Influence of college students' locus of control on altruism. China Electric Power Education. 137, 155-156. 
Zhang. Y. H. (2003). College students' locus of control and time management disposition. Psychological Science. 26 (3), 567-568.

Zhang, X. W. (2009). The relationship of college students' locus of control and mental health. Journal of Wuhan Commercial Service College. 23 (1), 60.
Zhao, G. Q. et al. (2007). On the relationship between psychological control and mental health. China Preventive Medicine. 8 (4).

Zhu, H. L. (2008). College students' locus of control and its influence: an experimental research. China Adult Education. 12, 106-107. 